\title{
ACtion Learning For Crime Prevention: IMPLICATIONS FOR COMMUNITY SAFETY
}

\author{
Nomazulu Ngozwana, Lindiwe Ngcobo and David Jele \\ Department of Adult Education, University of Eswatini, Kwaluseni, Eswatini
}

\begin{abstract}
Crime prevention is everyone's responsibility - law enforcement officers, community members, social groups, businesses and governments who all need to be sensitized about prevention strategies for ensuring community safety. Interpretive paradigm was used within a qualitative research approach. We adopted a descriptive research design. A semi-structured interview guide was used to collect data from all the participants that were purposively chosen. Six crime prevention officers, that were selected using snowball sampling, were individually interviewed. Data were further collected from twenty-eight members of community policing forums in three focus group discussions and six members of the inner council in the fourth focus group discussion. Qualitative thematic analysis was used. The findings revealed that some community policing forum members abused their skills and knowledge to commit crime than fight it. The findings demonstrated that community policing is effective in reducing crime. However, it transpired that the forums faced several challenges such as: lack of airtime to make calls, lack of incentives to motivate members, female members experiencing difficulty at night because they were afraid while others were not released by their partners to go to work. Although the community policing forums enhanced social change towards crime in various communities, there are negative implications for women serving as members of the forums.
\end{abstract}

\section{KEYWORDS}

Action Learning; Crime Prevention; Community Safety; Community Policing; Adult Learning

\section{INTRODUCTION}

All countries experience crime, which may lead to situations where people are killed and some family members losing a parent or having the latter being imprisoned. Moreover, factors such as poverty, disparity, greed, deprivation, unemployment, illiteracy or inadequate education, corruption and disregarding the rule of law increase the possibility for people to turn to crime (United Nations Office on Drugs and Crime (UNODC 2008). Eswatini is affected by some of these factors, which is why crime has been on the increase in the recent years (Sibisi, 2017). In the same way, all countries endeavour to ensure their citizens protection and to increase the quality of their lives (UNODC, 2010). In Eswatini like other countries, law enforcement is primarily the responsibility of the Royal Swaziland Police Service (RSPS) that was established by the Police Act No 29 of 1957, which has been renamed Royal Eswatini Police Service (REPS) in 2018 when the country's name changed. One of the key objectives of REPS is to detect and prevent crime and ensure community safety. It does that in partnerships with stakeholders for preserving public peace and order and through prevention of crime (RSPS, 2007). Thus, in order for REPS to achieve their goal, a department that focuses on reducing and preventing crime was established.

Crime prevention is everyone's responsibility - law enforcement officers, community members, social groups, businesses and governments who all need sensitization about prevention strategies 
for ensuring community safety. This emanates from the belief that crime and community safety issues emerge from local, specific contexts (Jamieson, 2008) and so are well managed at the community level. Moreover, local community members experience crime challenges directly and therefore, can have valued information that may be critical to the achievement of an intervention. While on the other hand, the long term success and sustainability of positive change in communities is inseparably linked to the extent of community engagement and ownership of approaches such as action learning.

Action learning is a continuous process of learning and reflection with an intention of getting things done (Liz \& McGill, 2013). The latter authors proclaim that through action learning individuals learn with and from each other by working on real problems and reflecting on their own experiences. The above is similar to what Marquardt and Banks (2010) emphasize about action learning which they see it as "a process and tool that enable individuals and groups to learn while solving problems and implementing actions" (p. 160). The authors' explanation involves two key issues: a process and a tool, while the former authors focused on the process that helps people to take an active stance towards life and helps to overcome the tendency to think, feel and be passive towards the pressures of life (Liz \& McGill, 2013). What these conceptions mean is that community participation is important in changing attitudes, empowering and mobilizing the members towards jointly positive safety measures. Therefore action learning cannot be overemphasized. This paper presents the findings from a study that was conducted in Eswatini, which focused on action learning by community policing forums and their contribution in preventing crime. The objectives were: to find out if community policing forums were effective or not in reducing crime; and to document experiences shared by community policing forums pertaining to their work of preventing crime and ensuring community safety. Literature review will be discussed, followed by the methodology then findings and discussion before the concluding remarks.

\section{LiterATURE REVIEW}

Literature reviewed concepts of crime prevention, community policing and action learning.

\subsection{Crime Prevention}

Crime prevention means many different things to different people. According to Welsh and Farrington (2012) crime prevention is regarded as any means of preventing crime or criminal offence from happening, meaning before crime can be committed. The authors posit that a goal in crime prevention is to stop the incidence from happening. What further differentiates crime prevention from crime control is that prevention takes place outside the boundaries of the formal justice system. According to Sibisi (2007) during the establishment of crime prevention unit in Eswatini, there were police officers that were selected to be trained as leaders for the unit. It is stated that their mandate was to educate, design, implement and evaluate strategies to reduce crime. Sibisi indicated that these police did their work in partnership with other stakeholders such as anti-crime clubs for both school going and out of school youths within the communities (Sibisi, 2017) as well as community policing. Based on the above explanations, it is therefore expected that there should be certain benefits coming as a result of the implementation of crime prevention programmes, which reduction of crime should be one of them.

According to Ford (2013) crime prevention has a benefit of reducing fear of crime and increases the quality of life. Ford's sentiments are shared by Jamieson (2008) in his study about 'Factors related to successful mobilization of communities for crime prevention' which proposes that community mobilization for crime prevention focused largely on issues of community safety and 
their well-being that engaged internal and external stakeholders of the community at hand. It is noted that through the collaboration of both internal and external stakeholders in crime prevention, the root causes of crime can be easily tackled by both communities and the police in a joint effort. On a contrary, Manaliyo (2016) posit that crime prevention is faced with challenges such as failure to mobilize the local communities to voluntarily participate in the policing programmes.

\subsection{Community Policing}

Community policing is a strategy whereby police officers are partnering with community members in fighting crime, instead of community members folding their arms and waiting to be helped (Mabuza, 2019). To achieve the goals of community policing, community policing forums were instituted, which are people who live in the communities and have been selected and entrusted by the entire community and chiefdom authorities to help the police in the reduction and fighting against crime (Sibisi, 2017; Mabuza, 2019). Additionally, the authors indicate that the chosen people are trained and monitored by crime prevention unit. However, it is worth mentioning that members chosen to join the community policing forums are not screened to check whether they have crime records or not. Community policing has five characteristics namely, service orientation (police seen as service providers while communities are clients, whose needs should be catered for), problem solving (joint analysis of causes of crimes), empowerment (educated for the joint capacity for addressing crime), partnerships (a cooperative effort to establish community representatives) and accountability (taking full responsibility for crime by both police and forums) (RSPS, 2008; Sibisi, 2017; Mabuza, 2019).

In the light of the above characteristics, community policing forums have thus played a role in fighting crime in Eswatini in partnership with the police officers. However, the contribution made by them alone including their actions is not known.

\subsection{Action Learning}

Action learning is one approach that can be used to address the challenge of improving crime prevention/community policing in different communities. Action learning seeks to facilitate skills development based on integration of knowledge gained from experience and knowledge gained by formal, informal or non-formal learning, underlined by critical reflection. Action learning is thus rooted in the theory and practice of adult learning (Kellihe, 2014). According to Marquardt and Waddill (2004) some adult learning theories apply more than others in the analysis and description of action learning, which uses theories, principles and practices of the former. Action learning is discussed using Marquardt's approach to action learning that is built around six components: (1) a problem or challenge of importance to the group; (2) a group of 4-8 members, ideally from diverse backgrounds and/or parts of the organization; (3) a process that emphasizes questions and reflections; (4) the power to take action on strategies developed; (5) a commitment to learning at the individual, team and organizational levels; and (6) an action learning coach who focuses on and ensures that time and energy are devoted to capturing the learning and improving the skill level of the group (Marquardt, 1999, 2004). Action learning can be described as a continuous group-based process of engagement, learning and reflection where a group of peers meets regularly under the guidance of a trained facilitator over an extended time period.

Additionally, action learning is further discussed drawing from social learning principles such as (1) attention and focus matter; (2) retention depends on the context; (3) reproduction occurs on demand; and (4) motivation can be intrinsic or extrinsic (Bandura, 1977, 1986). In action learning groups, participants bring real problems to the discussion with the aim of generating innovative 
and creative ways of dealing with complex problems (McGill \& Brockbank, 2003) and facilitating learning through the development of practical solutions that are implemented with planned intent (Ashton, 2006). In this case the community policing forum members meet on regular basis during their training by the police officers and even when sharing information pertaining to their work of fighting crime in their communities. This is where the forum members learn some strategies together and also share the solutions towards the encountered day to day challenges. Sessions are conducted in a Socratic manner, such that participants discuss their problems in a constant back and forth questioning and answering process that elicits critical thinking, and dialogue that encourages generation of ideas and clarification of assumptions (McGill \& Brockbank, 2003). Thus the pattern follows the philosophic sagacity by some African philosophers such as Mohlomi who was considered a wise man as he used the wisdom of other men in solving issues (Sefotho, 2018) through the African traditional wisdom.

Moreover, the process of action learning encourages community forum members to reflect on and learn from their own individual experiences and those of their peers (McGill \& Brockbank, 2003). People learn more and better when learning takes place practically than when passively being provided with information (Michel, Cater \& Varela, 2009). This can be attributed to the social context where community policing forum members effectively take action, learn how to work together in teams and become competent members. Additionally, action learning technique has been shown to improve confidence, resilience, conflict resolution, team work and empowerment that are all acquired as a result of social learning. For Marquardt and Waddill (2016) all forms of action learning share the elements of real people resolving and taking action on real problems in real time, and learning through questioning and reflection while doing so. In action learning, the most valuable learning occurs when action is taken, for one is never sure if the idea or plan will be effective until it has been implemented (Pedler, 1997).

\section{Literature REviEW}

\subsection{Paradigm and approach}

The study used interpretive paradigm under descriptive research design to give a detailed account (Rakotsoane, 2019) of the community policing forums and their contribution in preventing crime. A qualitative research approach was used in a small scale research that involved three communities in Manzini Region, Eswatini. The study described how community policing forums engage in action learning as a strategy to prevent crime and ensure community safety.

\subsection{Sampling and Data Collection methods}

Participants in each action learning group were purposively selected to participate in the focus group discussions, based on their willingness to share their thoughts and experiences as members in those community policing forums. In-depth individual interviews were conducted with six crime prevention officers who were purposively and further sampled through a snowball sampling. Purposive sampling also applied to select the six males who were inner council members who participated in a focus group discussion. Purposive sampling was further used with three community policing forums from the three different communities that participated in three focus group discussions. The first and second focus groups had ten members in each group (all males) while the third focus group had eight members (four females and four males). A semistructured interview guide was used with all the participants. 


\subsection{Data Analysis}

Qualitative thematic analysis was used to analyse the data. Braun and Clarke (2006) describe thematic analysis as 'a method for identifying, analysing and reporting patterns (themes) within data' (p. 79). It allows the researcher to organise data into codes and themes from both an inductive and deductive approach. Thematic analysis follows a series of steps including familiarising yourself with your data, generating initial codes, searching for themes, reviewing themes, defining and naming themes and producing the report (Braun and Clarke, 2006).

\subsection{Ethical Consideration}

The following ethics were considered when handling the interviews and focus group discussions with participants: confidentiality, anonymity and free withdrawal from participating without consequences. Permission to video record the focus group members were granted and all the participants gave their informed consent through verbal and by signing the informed consent forms to participate. The individual interviews with Police Officers were audio-recorded with their permission. There was no revealing of names and all participants were given codes that were used when transcribing and presenting the data.

\subsection{Limitations}

The sample was too small and therefore the findings cannot be generalised to all other communities in the Manzini Region. However, there may be similar patterns pertaining to the responses received if the study can be replicated to other communities in the same region.

\section{FINDINGS}

A number of themes emerged from the interviews and focus group discussions and were grouped under broad categories of inputs, processes and outcomes. Under the inputs, crime is a major issue with sub-themes such as: effective community policing forums in preventing crime; challenges experienced by community policing forums; abuse of skills and knowledge by the forum members. Under processes there are sub-themes such as: benefits gained from action learning within the context of CPF work; and trust among members. Then improved community safety is classified under the outcomes. These categories are discussed in order, the first being inputs.

\subsection{Inputs}

It was noted from the data that CPF have effectively managed to prevent crime in a number of ways. One inner council member attested that:

The CPF is an important resource because we live in a very eventful world these days. We assign them $[\mathrm{CPF}]$ to provide security to any kind of event that has a potential of criminal activity like weddings and funerals. I am reminded of a day when one man was caught on the act trying to break into a parked car at a night vigil... I cannot go into details because we are all relatives here (Inner council FGD, participant B)

Another member interjected:

As I speak I am the one guarding the chiefdom (umphakatsi) since there are threats that people want to burn it down, so I have to be there day and night in the absence of anyone except for the weekends (Inner council FGD, participant A) 
The community policing forum is doing a commendable job even though some people do not appreciate. The fact that there is someone to immediately think of in the community when one is in trouble, makes us feel safer unlike when you would sort yourself. In my observation they $[\mathrm{CPF}]$ are not supported enough, otherwise they [CPF] can do even better (Inner council FGD, participant E)

The above responses show that CPF reduce and prevent crime from occurring in some instances, indicating that the forum members are contributing immensely in crime reduction and ensuring for community safety as they are better placed in communities than the police officers. However, it was also observed that despite the efforts by CPF, crime has escalated in some areas due to some development initiatives in some communities. This has brought several challenges as indicated in the data below:

If relocating was that simple and would not require finances, I would have left this place for another one where criminal activities were better. Here, there is no day that passes without crime reports (CPF member, FGD community B)

Development is essential for every community but it comes with consequences of crime and other things. This area expressed excitement when Sappi Usuthu started the forest next to our place since people thought of job opportunities...but that turned the other way round and brought crime than before. Stock is stolen in the forests (Inner council FGD, participant D)

The above data reveal that some areas experienced challenges of high crime reports than others. There were other challenges expressed by some members as follows:

Working as a member of the forum does not bring anything for me except hatred by members of the community...s so who can tolerate to be hated while not getting any reward? The answer is no one... so if things were going my way, I would step down...but I am doing this for the respect of my chiefdom... (Male CPF, FGD community A)

Another member added:

This work is very dangerous especially for someone who do not have required equipment such as guns for protecting ourselves... we lack airtime to call the police, there are no incentives but we sacrifice and put our lives at risk while we do not get anything in return... (Male CPF, FGD community A.

I don't attend reports at night because my husband does not permit me and if I insist he suspects me of having extra-marital affairs (Female CPF, FGD community C)

The above data designate that forum members saw their work of community policing as one that deserved to be rewarded. Perhaps this was necessitated by that the work took all their time, involved challenges of putting their lives at risk and also had to use their airtime when calling the police whenever necessary. Accordingly, there was a notion that some community forum members were abusing their policing skills and knowledge by actually committing crime instead of fighting it. This came from two different focus group discussions, showing the seriousness of the problem. These criminal activities by some community policing forum members may be propelled by their lack of incentives, since they are not remunerated as they serve as volunteers. It may be likely that they could join criminal activities in an effort of raising income to meet their basic needs. 
It is annoying to discover that a person who is entrusted with this duty [of CPF] but who betray the other hardworking members by giving suspected people some tips and information and protecting them with the intention of getting paid (Male CPF, FGD community B).

The challenge of unemployment is a trouble for our CPF members because they turn to indulge into drinking the cheap home brewed [beer] where most crimes occur... and they are [crimes] not reported because such members address them there and [they] stop calling police because a lot will transpire, like those trading without licences (Inner council FGP, community A)

The above responses suggest that some CPF members do not take their work seriously and do not fully commit, which shows lack of motivation that is needed to encourage them. It is noted that $\mathrm{CPF}$ members are selected in various communities, however with no specific criteria for choosing deserving members in the whole process.

\subsection{Processes}

In this category, there were sub-themes such as benefits of action learning within the context of CPF work; and trust among members. For the benefits of action learning, several participants expressed that action learning was empowering and gave them confidence, assertiveness and a sense of independence. They revealed that group meetings empowered them to be proactive in finding solutions to challenges in their work and made them more confident to share ideas and mobilize other members to support new approaches to solving problems. Participants also stated that action learning empowered them to approach their partners (police officers) with ideas on how to improve strategies of preventing crime in the communities. Almost all the participants mentioned that they had developed confidence through participating in the action learning sessions and that they applied the competencies in their work. One community policing forum member stated:

No, before that I didn't have that confidence, you know, but after I've started engaging in this action learning I became so grateful, you know, and have that confidence that really I'm going... ... (Male CPF in FGD 2, Community B).

Another participant also shared similar sentiments about the benefits of action learning in relation to their community policing work.

Working together and sharing information made me confident...assertive and confident, that process actually makes one become stronger in the whole process... (Male CPF in FGD1, Community A).

I like this work very much because it came with a lot of benefits for me... ever since I became a member no one has ever dreamt of committing crime in my home... I think they are afraid [of me] another thing is the respect I get from people that makes me feel a sense of high status (Male CPF in FGD 3, community C)

The above data demonstrate the member expressing his comfort in being a forum member in that he feels protected from crime by virtue of being a member. On the issue of benefits, one crime prevention police officer validated by saying:

As far as I see this, community policing forums make the police work to be easy, and with them $[\mathrm{CPF}]$ the friction that used to exist between the police and the communities is minimal these days (Interview, Crime Prevention Police Officer 2) 
It can be noted from the above data that in action learning, problems are solved within a group of individuals who diversely interact and therefore share various opinions.

Trust among the group members was another key feature that was identified by participants. As a result of the similarity of the challenges experienced by participants and their frequent meetings, participants learned to trust one another and developed lasting relationships that continued beyond action learning.

On a contrary, trust was an issue of concern where some CPF members stated that police were unethical in the process of community policing. One said:

The police do not practice what they preach. They teach us to call them in cases of emergency and that they will be there but that is not happening practically. We call them today and they come tomorrow... The police also sell us out to the suspects by revealing us as their informers and thereafter deny having done that... (Male CPF, FGD community C).

The above response shows that the police do not honour their stipulated time of attending crime thus breaking trust and hope in them. Moreover the data reveal that the police lack customer care skills, confidentiality and work ethics which all compromise the impact of policing outcomes.

\subsection{Outcomes}

Despite the above sentiment indicating that some members and some police were compromising processes of policing, the work done by community policing forums cannot be overemphasized. It was worthy to note that the work of community policing forums improved community safety generally. One member illustrated this:

The community policing forum members should not look down upon themselves because this programme was meant for community members to discover their potential to solve their criminal problems and improve their community safety. It is my belief that one day a piece of legislation will be enacted for them [CPF] like in other countries (Interview, Crime prevention police officer 2)

The above response demonstrates that there is no law that is guiding the practices and operations of community policing forums, which could be a solution to some challenges they face.

Action learning provided a platform for participants to develop problem-solving skills that they could then practically apply to manage their work more effectively. Participants also mentioned that the iterative way of interrogating a challenge brought to the group, improved their critical thinking skills which were applied to their work challenges in order to develop relevant solutions. Moreover, these skills encouraged the participants to take initiative in their work because they did not rely on police officers to propose ideas on how to tackle challenges.

\section{Discussion}

The findings suggest that community policing forums contribute in reducing and preventing crime in communities of Manzini, Eswatini. These forums seemed to be working in different communities as a resource for police by providing security to some events taking place in communities, give information to the police or even make calls on emergency cases among other duties. It was revealed that community policing forums serve in their communities thus have 
reduced the fear of crime as they are known to be there unlike the police who are not residing in communities where crime takes place. The findings concur with suggestions by Jamieson (2008).

On the other hand community policing forum members faced challenges of handling escalating crime especially in developing communities. The challenges were overwhelming and included hatred of forum members by members of the public while doing their work. Some members indicated their dilemma of not dropping the work due to obedience to their chiefdoms. It transpired that the work done by community policing forums was dangerous, risky not issued with necessary work equipment to protect themselves from these difficulties. The findings revealed that community policing forum members were not rewarded, not given incentives to motivate and encourage them to do their work properly, instead used their airtime to call the police, thus impoverishing them even more. These findings supported Manaliyo (2016).

On the light of the above challenges, some members of the forums were not taking their work seriously and lacked commitment as the findings illustrated that some drank too much, hide information or give suspects tip offs or even turn to crime by abusing the skills and knowledge they received when they were trained. This is supporting the UNODC $(2008,2010)$.

Despite the above challenges faced, the findings demonstrated the benefits received from action learning by forum members when interacting and working together to fight and prevent crime. The members' confidence was built, they earned respect from the public while some expressed their comfort as they were protected and supported one another through sharing information in the meetings they held together. That portrayed an African cultural way of engaging together when tackling problems, which also facilitated issues of trust among members (Sefotho, 2018; Ford, 2013).

Contrarily the police were found to be lacking the customer care whereby they revealed the forum members to the suspects, delay to attend scene of crimes thus compromising the work ethics. Police were no longer trustworthy as they lacked confidentiality, thus disturbing the operation of the CPFs. Despite all what was revealed, the CPF members made the work of the police easy. This was pointed out by the outcomes where forums served as programmes that generally improved community safety in various communities. However, it was noted that there was no regulation or law that guided the operation of the forums. That had a serious implication starting from the criteria used to choose members who voluntarily joined the forums.

\section{Concluding Remarks}

While community policing forums are doing a great job pertaining to community safety measures, it is important to realize the importance of individual internal transformation in this whole situation. This means that change starts from within, from the internal self in every effort done by groups, which might not be addressed in the training received by CPF from the police. The following recommendations are made:

(1) The number of CPF members must be increased so that more strategies can be put in place, such as neighborhoods watch teams.

(2) Communities must encourage participation of young people as members of the forums in all the communities and members should be screened.

(3) Communities need to re-visit the work of female members serving in the forums. 
(4) Training and action learning by CPF should start by focusing on individual's change of character to boost their intrinsic motivation when serving and exercising responsible citizenship in ensuring for their community safety.

\section{REFERENCES}

1) Ashton S. (2006). Where's the action? The concept of action in action learning. Action Learning Research and Practice. 3(01):5-29. doi: 10.1080/14767330600574565

2) Bandura, A. (1977). Social learning theory. Englewood Cliffs: NJ, Prentice-Hall.

3) Bandura, A. (1986). Social foundations of thought and action: A social cognitive theory. Englewood Cliffs, NJ, Prentice-Hall.

4) Bandura, A. (1989). Social cognitive theory. Annals of child development. R. Vasta. Greenwich, CT: Jai Press, Ltd. 6: 1-60.

5) Dilworth, R. L. \& V. J. Willis (2003). Action learning: Images and pathways. Malabar, FL: Krieger.

6) Dotlich, D. and J. Noel (1998). Action learning: How the world's top companies are re-creating their leaders and themselves. San Francisco: Jossey-Bass.

7) Ford, S. (2013). Benefits of crime prevention. Accessed from http://www.acpc.org.au/images/documents/benefits-of-crime-prevention.pdf

8) Freire, P. (1973). Education for critical consciousness. New York: Seabury Press.

9) Jamieson, W. (2008). Factors related to successful mobilization of communities for crime prevention, IPC Review, Vol2, pp. $11-33$.

10) Kelliher F. (2014). Just do it: action learning as a catalyst for reflective learning on an MBA programme. Procedia - Social and Behavioral Sciences.141:1275-1280. doi: 10.1016/j.sbspro.2014.05.220

11) Knowles, M. S. (1970). The modern practice of adult education: Andragogy vs. pedagogy. New York: Association Press.

12) Knowles, M. S. (1984). Andragogy in action. San Francisco: Jossey-Bass Publishers.

13) Lave, J. \& Wenger, E. (1990). Situated learning: Legitimate peripheral participation. Palo Alto: Institute for Research on Learning.

14) Liz, B. \& McGill, I. (2013). Action learning. A Practitioner's Guide, McGill, Ian.

15) Mabuza, T. (2019). Assessment of the Contributions and Challenges of Community Policing Forums in Reducing Crime in Eswatini: A case of Manzini Region. Unpublished Research Project submitted in Partial Fulfilment of the Diploma in Adult Education of the University of Eswatini.

16) Manaliyo, J.C. (2016). Barriers to community participation in crime prevention in low income communities in Cape Town. International Journal of Social Sciences and Humanities Studies, Vol 8, No1, ISSN: $1309-8063$.

17) Marquard, M. J. \& Banks, S. (2010). Theory to practice: Action Learning. Advances in Developing Human Resources, 12(2), 159 - 162, DOI: 10.1177/1523422310367878

18) Marquardt, M. J. \& Waddill, D. (2004).The power of learning in action learning: A conceptual analysis of how the five schools of adult learning theories are incorporated within the practice of action learning in in Action Learning Research and Practice. DOI: 10.1080/1476733042000264146

19) Marquardt, M. J. (1999). Action learning in action: Transforming problems and people for worldclass organizational learning. Palo Alto: Davies-Black Publishing.

20) Marquardt, M. J. (2000). Action learning and leadership. The Learning Organization, 7, (5): 233-240.

21) Marquardt, M. J. (2004). Optimizing the power of action learning. Palo Alto: Davies-Black Publishing.

22) McGill I, Brockbank A. (2003). Action learning handbook: Kogan Page.

23) Merriam, S. B., \& Caffarella, R. S. (1999). Learning in Adulthood (Second Ed.). San Francisco, California: Jossey-Bass.

24) Michel N, Cater JJ, Varela O. (2009). Active versus passive teaching styles: an empirical study of student learning outcomes. Hum Resour Dev Q. 2009;20(4):397-418. doi: 10.1002/hrdq.20025

25) Pedler, M., (Ed.) (1997). Action learning in practice. Aldershot: Gower.

26) Rakotsoane, C. L. (2019). Research made simple: A step-by-step guide for Research-Writing. Morija Printing Works: Morija-Lesotho.

27) Revans, R. W. (1982). The origin and growth of action learning. London: Chartwell Bratt. 
International Journal of Education (IJE) Vol.8, No.4, December 2020

28) Royal Swaziland Police Service (2007). Crime Prevention, The Royal Swaziland Police Newsletter, Vol 2, No 6, May/June.

29) Sefotho, M. M. (2018). Philosophy in education and research: African perspectives. Van Schaik Publishers: Pretoria.

30) Sibisi, L. (2017). The effectiveness of crime prevention programmes of the RSPS, Eswatini, Unpublished Research Project submitted in Partial Fulfilment of the Diploma in Adult Education of the University of Eswatini.

31) United Nations Office on Drugs and Crime (2010). Handbook on the crime prevention guidelines: Making them work. United Nations: New York.

32) United Nations Office on Drugs and Crime. (2008). Handbook on planning and action for Crime Prevention in Southern Africa and the Caribbean Regions. United Nations: New York.

33) Weinstein, K. (1995). Action learning: A journey in discovery and development. London: Harper Collins.

34) Welsh, C.B. and Farrington, D.P. (2012). Criminology and Criminal Justice, Crime Prevention, In Crime Prevention and Public Policy, The Oxford Handbook of Crime Prevention. DOI: 10.1093/oxfordhb/9780195398823.013.0001.

Corresponding author: Nomazulu Ngozwana

Contact email: nomazulungozwana@gmai.com

\section{AUTHORS}

Nomazulu Ngozwana

Lindiwe Ngcobo

David Jele 